\title{
An Empirical Analysis of Volatility Characteristics of Inter-Bank Offered Rate of International Financial Centers
}

\author{
Maoguo $\mathrm{Wu}^{1} \&$ Xin Luo ${ }^{1}$ \\ ${ }^{1}$ SHU-UTS SILC Business School, Shanghai University, Shanghai, China \\ Correspondence: Xin Luo, SHU-UTS SILC Business School, Shanghai University, 20 Chengzhong Road, Jiading \\ District, Shanghai 201899, China.
}

Received: September 22, 2016

Accepted: October 10, $2016 \quad$ Online Published: October 15, 2016

doi:10.5430/ijfr.v7n5p176

URL: http://dx.doi.org/10.5430/ijfr.v7n5p176

\begin{abstract}
This paper compares the trails of volatility of the inter-bank offered rate of five international financial centers with that of Shanghai Inter-Bank Offered Rate (Shibor), using VaR-GARCH model. Considering the influences of local lending rate system and economic environment, it also provides policy implications to improve the pricing approach of Shibor and the revolution of marketization of interest rate, and to increase the reference value of Shibor. Previous research usually analyzes the volatility of the lending rate of one or two markets with the same currency. However, this paper compares Shibor with lending rates of five different global financial centers, which helps correct Shibor's pricing system and the market it involves. Moreover, this paper uses various kinds of models from the GARCH family to find the optimal one for each market, instead of modelling all different rates with the same model. By doing so it can obtain the model which matches each market best and increase the accuracy of the results.
\end{abstract}

Keywords: GARCH Model, VaR Model, inter-bank rate, traits of volatility

\section{Introduction}

After the financial crisis in 2008, the global financial market, particularly the banking sector, is in depression. Commercial banks have a pivotal position in the process of financial development. Since commercial banks have some special functions such as credit creation, the operation of the banks is based on various types of risks. Appropriate calculations of risk should be applied to ensure the sound operation of the banking system. This course of action will contribute directly to the development of financial market. Banks often deal with three main risks, i.e., credit risk, operational risk, and market risk. The main priority of China's government is to regulate the market risk and credit risk. Besides, appropriate measurement models of risk are required to be developed. Interest rate risk is a significant component of market risk. The main source of income of commercial banks is the spread income which consists of difference between deposit and lending interest rate. The pricing of differential between deposit and lending interest rate, mortgage interest rate and other business is referred to the inter-bank offered rate. Therefore, the volatility of inter-bank offered rate will result in the market risk of bank's operation, thus the profitability of commercial banks will be directly affected. The 13th Five-Year Plan for Economic and Social Development of the People's Republic of China points out that China should accelerate reform of the marketization of interest rate and expect Shibor can be used for financial products pricing. These actions indicate that the Chinese government expects financial institution to reduce the dependence on central bank's benchmark lending rate. China is in the process of reformation of market-oriented interest rate. Therefore, the volatility of interest rate will influence the pricing of interest-oriented products and the market risk of financial institution especially banking. People should concentrate on the method which reduce or avoid the volatility of interest rate risk. China pays a great deal of attention to Shanghai's financial market and Shibor. This paper attempts to find Shibor risk characteristics and explores the mechanism and measure which benefit the development of Shanghai financial markets through the analysis of volatility of several international financial centers' inter-bank offered rates.

\section{Related Literature}

There are serval studies involved risk and measurement of risk using GARCH model. Gu (2015) points out that commercial bank, which is a significant component of the financial market, mainly depends on the interest income. After the reformation of economic system, the competition of financial market is intensified. In this situation, measuring and standardizing interest rate risk becomes particularly important than ever. Sánchez-Fung (2004) studies 
the volatility of inter-bank offered rate daily in a big banking crisis in the Dominican Republic using GARCH model. It concludes that positive impact and negative impact bring similar effects at the time of financial stability whereas negative impact has more serious impact than positive impact at the time of banking crisis. According to the studies, asymmetric volatility index can indicate that the value of early warning index benefits daily supervision of the inter-bank market. Neupane (2011) studies the volatility of Nepal's interbank interest rates using GARCH $(1,1)$ model and finds that the distribution of that rate is non-normal distribution and that rate is dependent on time. Thenmozhi (2006) analyzes the commercial paper rates and Mumbai inter-bank offered rates (Mibor) using ARIMA, ARMA-GARCH and ARMA-EGARCH model. An appropriate prediction model is established for each interest rate. The result indicates that time series exists in fluctuation aggregation effect and the proper models are GARCH-related. The ARMA-EGARCH and ARMA-GARCH model are appropriate for the commercial paper rates and Mibor, respectively. Olowe and Ayodeji (2011) utilizes GARCH (1,1), EGARCH (1,1), TS-GARCH $(1,1)$ and PARCH $(1,1)$ to analyze the volatility of Nigeria's inter-bank offered rates in the crash of stock market and global crisis. The result shows that the fluctuation is consistent but the positive impact and negative impact of Nigeria's inter-bank offered rates are symmetrical and there is no leverage. Therefore, the most appropriate model is TS-GARCH model.

With the development of China's economy and the openness of financial market, there are several papers which study the risk of interest rate fluctuation. Tan (2013) concludes that the interest rate risk commercial banks suffer from becomes more significant because of the complexity of the fluctuation of interest rate. Moreover, as the degree of market-based reform of interest rates increases, the risk that financial institutions bear is increasing. Guo (2014) proposes that with the promotion of market-based reform of interest rates, investment activities need increasing amount of capital to satisfy its development. Due to the increase in frequency of transaction amounts financial institutions, the widely-used inter-bank offered rate will suffer from more risk than ever, indicating that the fluctuation of rate is more significant. Chen (2012) points out that commercial banks' sense of risk management is relatively low and the corresponding supervision is weak as well. To deal with the interest rate risk, this paper suggests using the way of measuring the risk of interest rate to establish the corresponding system of risk management. Jia (2007) concludes that the soundness of inter-bank offered rate market has a close relation with national financial markets. Additionally, Long (2009) studies the Shibor as the benchmark interest rate and finds that Shibor has certain degree of feasibility in theory and practice while it lacks some mechanism. Yang (2013) points that China is in the process of market-based reform of interest rates. Therefore, there are still several relevant systems which should be improved. Li and Ma (2007) indicate that using VaR can effectively disclose the degree of interest rate risk in financial market because the application of $\mathrm{VaR}$ is relatively mature. Xu (2011) discloses that VaR fills defects of traditional methods of risk measurement since VaR can measure the maximum loss of portfolio in a common market. Chen (2012) believes that Shibor has the potential to become the benchmark interest rate of the market.

\section{Overview of International Financial Centers and the Inter-Bank Offered Markets}

\subsection{Rankings of International Financial Centers}

Financial centers include financial intermediaries (such as banks), institutional investors (such as investment manager), and central bank. A financial center is a place where financial markets and financial activities take place and gather. Financial transactions, such as insurance, foreign exchange, and bonds, are carried out systematically in financial centers. Currently, there are several rankings of financial centers in the market. Global Financial Centers Index (GFCI) and the International Financial Centers Development Index(IFCDI) are the two major index that evaluate the rankings of international financial centers. Table 1 shows the two index.

Table 1. Global Financial Centers Index (GFCI) and the International Financial Centers Development Index (IFCDI) in 2015

\begin{tabular}{|c|c|c|c|c|c|}
\hline \multicolumn{3}{|c|}{ Global Financial Centers Index } & \multicolumn{2}{|c|}{ Index } & Development \\
\hline Ranking & Center & Score & Ranking & Center & Score \\
\hline 1 & London & 796 & 1 & New York & 87.72 \\
\hline 2 & New York & 788 & 2 & London & 86.64 \\
\hline
\end{tabular}




\begin{tabular}{llllll}
\hline 3 & Hong Kong & 755 & 3 & Tokyo & 84.57 \\
4 & Singapore & 750 & 4 & Singapore & 77.23 \\
5 & Tokyo & 725 & 5 & Hong Kong & 77.10 \\
6 & Seoul & 724 & 6 & Shanghai & 77.10 \\
7 & Zurich & 715 & 7 & Paris & 64.83 \\
8 & Toronto & 714 & 8 & Frankfurt & 60.27 \\
9 & San Francisco & 712 & 9 & Beijing & 59.98 \\
10 & Washington & 711 & 10 & Chicago & 58.22 \\
\hline
\end{tabular}

Table 1 shows that some financial centers appear in both index, such as London and New York. Beijing and Shanghai are listed in International Financial Centers Development Index ranking, indicating the excellent prospects of Chinese financial market. In particular, the ranking of Shanghai is higher than that of Beijing. Therefore, Shanghai is selected as an international financial center and compared with other international financial centers.

\subsection{International Financial Centers' Inter-Bank Offered Rates}

In this paper, interbank offered rates of London, Tokyo, Seoul, Toronto, Canada, New York, San Francisco, and Washington are compared with Shibor in terms of risk characteristics.

\subsubsection{London Inter-Bank Offered Rate}

London has been ranked as a leading international financial center since the 19th century. During this period, London has become the world's main lending and investment center. London remains a leading position in the international financial center, maintaining the largest global financial services trade surplus. It has the largest financial derivatives market, foreign exchange market, money market, international bond issuance and international bank lending center. London Inter-Bank Offered Rate (LIBOR) is an ideal representative in inter-bank offered rate. LIBOR is used as a benchmark of commercial loans, mortgages, and debt interest rate.

\subsubsection{Tokyo Inter-Bank Offered Rate}

With its economic development, Tokyo became a major financial center in the 1980s. Short-term, long-term capital market, foreign exchange market and the US dollar short-term lending market in Tokyo make up the financial market of Tokyo. The financial market of Tokyo has close relation with New York and London. Overnight call rate is the benchmark interest rate in Japan and it is regulated by central bank of Japan.

\subsubsection{Federal Funds Rate}

Since the 20th century, New York has been a leading international financial center. New York was ranked as the top international financial center in November 2014. New York has the largest trading center of public assets and debt capital markets and possesses New York Stock Exchange and National Association of Securities Dealers Automated Quotations (NASDAQ), two largest stock exchanges in the world. Federal Reserve Bank in New York is one of the largest Federal Reserve Systems in United States. It can adjust the financial mechanism and US monetary policy which affects the world economy. San Francisco is the fourth largest city in US. It is near the world-famous high-tech industrial zone, Silicon Valley. In the early twentieth century, the wealth from California Gold Rush San prompted Francisco to became the banking and financial center in the US West Coast. Many large financial institutions, multinational banks and venture capital firms have headquarters or regional headquarters in San Francisco. Washington is the capital and political center of the United States. This region has nearly 200 foreign embassies and international organizations such as World Bank and International Monetary Fund. One of the main reasons of economic development in Washington is the US capital identification which promotes employment and finance. Federal Funds Rate is the overnight call rate of inter-bank lending markets. Federal Funds Rate is not directly priced by The Fed but by negotiation between two banks. The Fed uses monetary policy tools on the money supply in the US economy. Moreover, Federal funds effective rate follows the change of federal funds target interest rate. Therefore, it can indirectly regulate the federal funds rate.

\subsubsection{Canada Inter-Bank Offered Rate}

Leading the financial market, Toronto possesses the largest financial institutions and large insurance companies in Canada. Because of the stable banking system in Canada, Toronto has become one of the fastest growing financial centers after the 2008 financial crisis. Most of the financial industries are gathered in Bay Street where Toronto Stock 
Exchange is located. Bank of Canada announces interest rate decision about benchmark interest rate adjustments.

\subsubsection{Korea Inter-Bank Offered Rate}

Seoul has become an international financial center since the 2008 financial crisis. In 2009, the Seoul International Financial Center was ranked No. 53. With the development of Seoul's economy, Seoul quickly caught up and ranked No. 7 in Global Financial Centers Index (GFCI) ranking in 2015. Seoul has the maximum growth rate among top 10 international financial centers.

\subsubsection{Shanghai Inter-Bank Offered Rate}

Shanghai used to be the number one financial center in the Far East before China liberation in 1949. The scale of the stock market, foreign exchange market and financial markets were the largest in Asia. However, capital markets closed due to the enterprise's public-private partnerships. Finally, some financial institutions such as Bank of Communications resumed to operate, signaling the restore of financial market of Shanghai. Currently, Shanghai financial market brings together a number of financial intermediaries such as Shanghai stock exchange, derivatives exchange, foreign exchange trading center, and clearing houses. In accordance with China's "Thirteen Five" plan, Shanghai will spare no effort to make itself a global financial center. Therefore, Shanghai will enhance its ability of financial resource allocation and the competitiveness of its financial market. Shanghai will also enhance its role in the global financial market and promote the degree of internationalization of Shanghai. China's central bank introduced Shanghai Inter-Bank Offered Rate (Shibor) in 2006. This interest rate depends on the mean of independent pricing of specific banks. The borrowing period of Shibor is between overnight and one year. As the Chinese financial market gradually recognizes Shibor, the power of pricing of Shibor is growing. Notes, bonds and derivatives are based on Shibor.

\section{Empirical Analysis of Volatility Characteristics of Inter-Bank Offered Rates}

\subsection{Data Selection and Description}

The selection of international financial centers is based on Global Financial Centers Index in September 2015. The details are listed in Table 2. This paper selects inter-bank offered rate of 5 different international financial centers such as LIBOR, Tokyo Inter-Bank Offered Rate, Federal Funds Rate, Canada overnight lending rate, South Korea overnight lending rate compares them with Shibor. It analyzes the fluctuation characteristics of all rates. Moreover, data show that each inter-bank offered rate has different lending term. Since inter-bank lending is mainly short-term lending, thus this paper chooses the shortest term of interest rate data in each market. Overnight lending rate is analyzed because of high liquidity and volatility. This paper calculates the mean of 5 days' market overnight rate. The mean treatment can reflect the central tendency of overnight lending rates and is conducive to its volatility analysis. In summary, this paper selects data of six international financial centers and analysis is based on the mean of 5 days' inter-bank offered rate. Detailed information is listed in Table 2.

Table 2. Inter-bank offered rates of six international financial centers

\begin{tabular}{|c|c|c|c|c|}
\hline Rate & Currency & Name & $\begin{array}{c}\text { Number of } \\
\text { Observations }\end{array}$ & Source of data \\
\hline $\begin{array}{l}\text { Shanghai Inter-Bank Offered } \\
\text { Rate }\end{array}$ & Renminbi & Shibor & 2,377 & $\begin{array}{c}\text { Shanghai Inter-Bank } \\
\text { Offered Rate Official } \\
\text { Website }\end{array}$ \\
\hline $\begin{array}{l}\text { London Inter-Bank Offered } \\
\text { Rate }\end{array}$ & GBP & Libor & 2,402 & $\begin{array}{c}\text { Federal Reserve Bank } \\
\text { of St. Louis }\end{array}$ \\
\hline $\begin{array}{l}\text { Tokyo Inter-Bank Offered } \\
\text { Rate }\end{array}$ & Yen & Tibor & 2,329 & Economic Database \\
\hline Federal Funds Rate & Dollar & FFR & 2,390 & $\begin{array}{c}\text { Federal Reserve Bank } \\
\text { of New York }\end{array}$ \\
\hline $\begin{array}{l}\text { Canada Inter-Bank Offered } \\
\text { Rate }\end{array}$ & $\begin{array}{l}\text { Canadian } \\
\text { Dollars }\end{array}$ & Cbir & 2,478 & Bank of Canada \\
\hline $\begin{array}{l}\text { Korea Inter-Bank Offered } \\
\text { Rate }\end{array}$ & Won & Kibor & 2,367 & Economic Database \\
\hline
\end{tabular}

NOTE: Because different financial centers have different national holidays, there are differences among the actual number of observations within the same period. 
Firstly, data description analysis is applied to analyze over each inter-bank offered rate. It generates an intuitive understanding of data. Table 3 shows the results.

Table 3. Description analysis of 5 days' inter-bank offered rates

\begin{tabular}{cccccc}
\hline Rate & Mean & Median & Maximum & Minimum & $\begin{array}{c}\text { Standard } \\
\text { Deviation }\end{array}$ \\
\hline Shibor & 2.353897 & 2.211700 & 8.364200 & 0.801400 & 1.012186 \\
Libor & 1.629396 & 0.548345 & 6.343750 & 0.437500 & 2.019378 \\
Tibor & 0.166089 & 0.085600 & 0.550200 & 0.008000 & 0.164441 \\
FFR & 0.964097 & 0.148000 & 5.306000 & 0.060000 & 1.707800 \\
Cbir & 1.490920 & 1.000000 & 4.500000 & 0.250000 & 1.334474 \\
Kibor & 2.924089 & 2.506000 & 5.256000 & 1.438000 & 1.130057 \\
\hline
\end{tabular}

As shown in Table 3, Shibor and Kibor have larger mean among the 5 overnight lending rates followed by Libor, Cbir, FFR and Tibor. In terms of dispersion, Libor has the largest volatility and Tibor has the smallest volatility.

\subsection{Fluctuation Characteristics of Overnight Lending Rate}

\subsubsection{Stationary Test}

In order to use econometric model to analyze time series data, the series must be stationary. The stationary of series is verified by the stationary test charts and unit root test. First of all, this paper draws a time sequence diagram for six different overnight lending rates, which are shown in Figure 1.
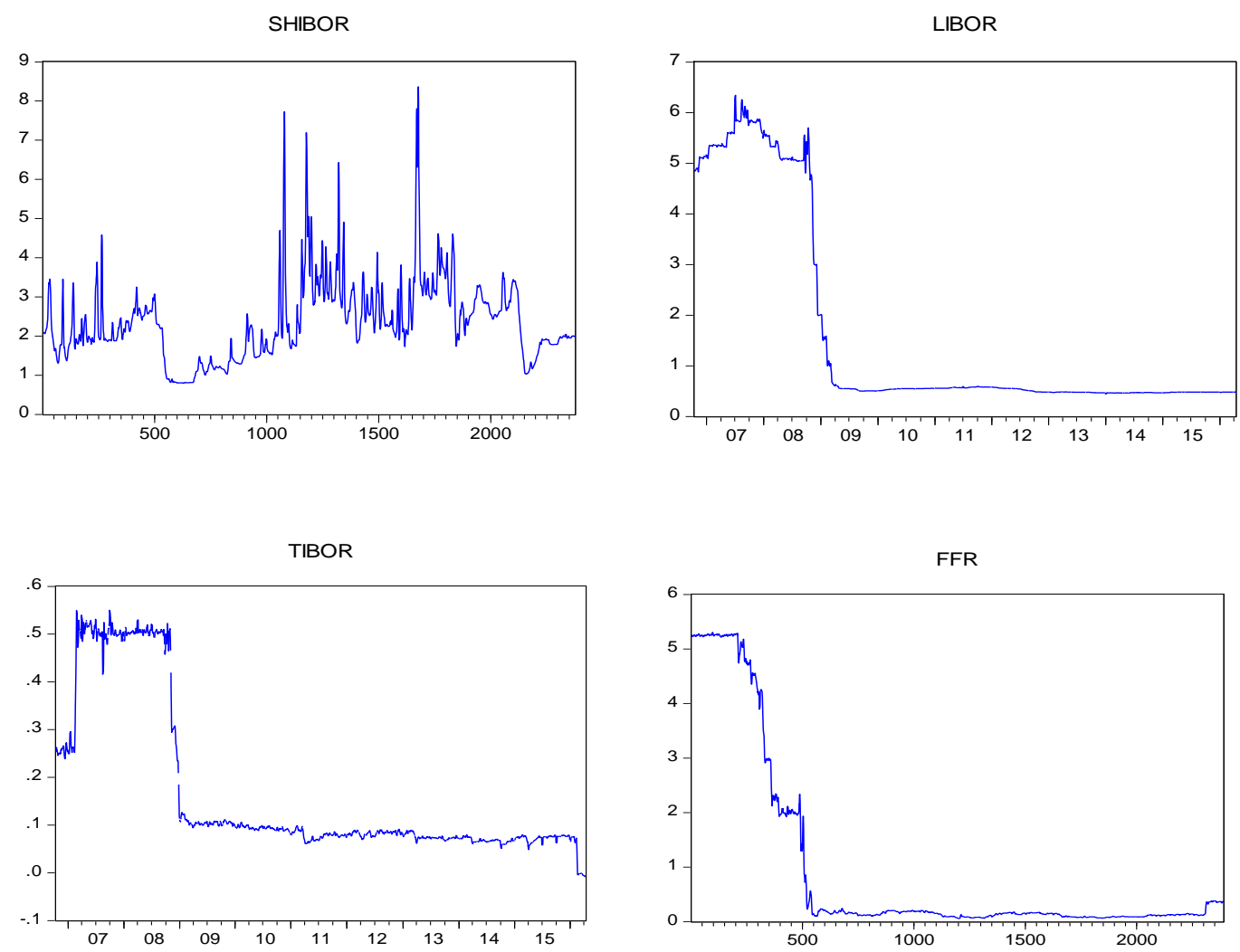

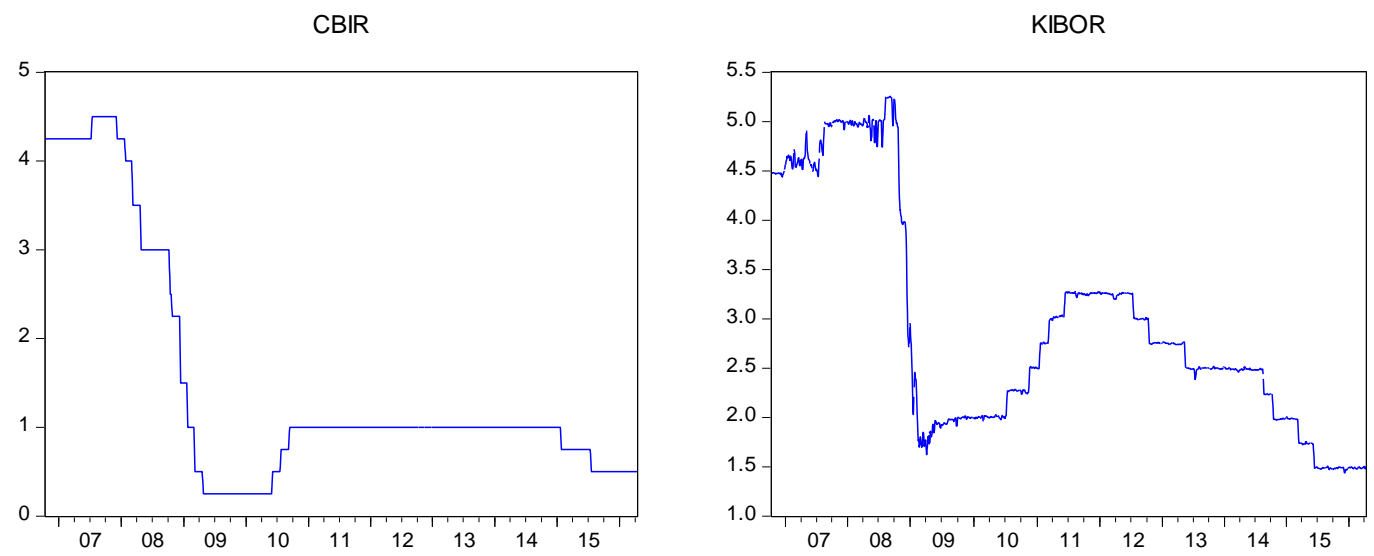

Figure 1. Time series of six different overnight lending rates

Figure 1 illustrates that six different inter-bank offered rates have no large fluctuation. Shibor possesses constant term but no trend items. Besides, Shibor has intensive fluctuation among these inter-bank offered rates. Libor, Tibor, FFR, Cbir and Kibor all have a period in which inter-bank offered rates have sharp fluctuations.

Unit root test determines whether constant term and trend item exist. Results of Augmented Dickey - Fuller Test (ADF) are showed in Table 4.

Table 4. Augmented Dickey-Fuller Test statistic

\begin{tabular}{|c|c|c|c|c|c|c|}
\hline \multirow{2}{*}{ Variable } & \multirow{2}{*}{$\begin{array}{l}\text { ADF } \\
\text { Statistic }\end{array}$} & \multicolumn{3}{|c|}{ Critical Value } & \multirow{2}{*}{ P-value } & \multirow{2}{*}{ Conclusion } \\
\hline & & $1 \%$ & $5 \%$ & $10 \%$ & & \\
\hline Shibor & -4.236647 & -3.432937 & -2.862569 & -2.567363 & 0.0006 & Stationary \\
\hline Libor & -1.570106 & -3.961901 & -3.411696 & -3.127726 & 0.8046 & Non-Stationary \\
\hline $\begin{array}{l}\text { First } \\
\text { Difference } \\
\text { Libor }\end{array}$ & -5.855049 & -3.432903 & -2.862554 & -2.567355 & 0.0000 & Stationary \\
\hline Tibor & -2.202314 & -3.962032 & -3.411760 & -3.127764 & 0.4875 & Non-Stationary \\
\hline $\begin{array}{l}\text { First } \\
\text { Difference } \\
\text { Tibor }\end{array}$ & -7.762521 & -3.432996 & -2.862595 & -2.567377 & 0.0000 & Stationary \\
\hline FFR & -1.586454 & -3.961929 & -3.411710 & -3.127734 & 0.7984 & Non-Stationary \\
\hline $\begin{array}{l}\text { First } \\
\text { Difference } \\
\text { FFR }\end{array}$ & -7.918114 & -3.432922 & 2.862562 & -2.567360 & 0.0000 & Stationary \\
\hline $\begin{array}{l}\text { Cbir } \\
\text { First }\end{array}$ & -1.411874 & -3.961789 & -3.411641 & -3.127694 & 0.8576 & Non-Stationary \\
\hline $\begin{array}{l}\text { Difference } \\
\text { Cbir }\end{array}$ & -6.477997 & -3.432824 & -2.862519 & -2.567336 & 0.0000 & Stationary \\
\hline Kibor & -1.925952 & -3.961967 & -3.411729 & -3.127746 & 0.6405 & Non-Stationary \\
\hline $\begin{array}{l}\text { First } \\
\text { Difference } \\
\text { Kibor }\end{array}$ & -5.937863 & -3.432950 & -2.862575 & -2.567366 & 0.0000 & Stationary \\
\hline
\end{tabular}

Since this paper analyzes the mean of each inter-bank offered rate, it must satisfy the assumption of classical linear regression model. Data must meet the following three conditions in order to ensure that the model results are linear 
unbiased minimum variance properties: error term has the same variance, follows normal distribution, and has no serial correlation.

\subsubsection{Normality Test}

This paper uses Jarque-Bera statistic for normality test. Under the null hypothesis (normal distribution) assumption, J-B statistic should obey 2 degrees of freedom chi-square distribution. If J-B statistics is large enough, then the sample data is not normally distributed. Detailed information is shown in Figure 2 and Table 5.
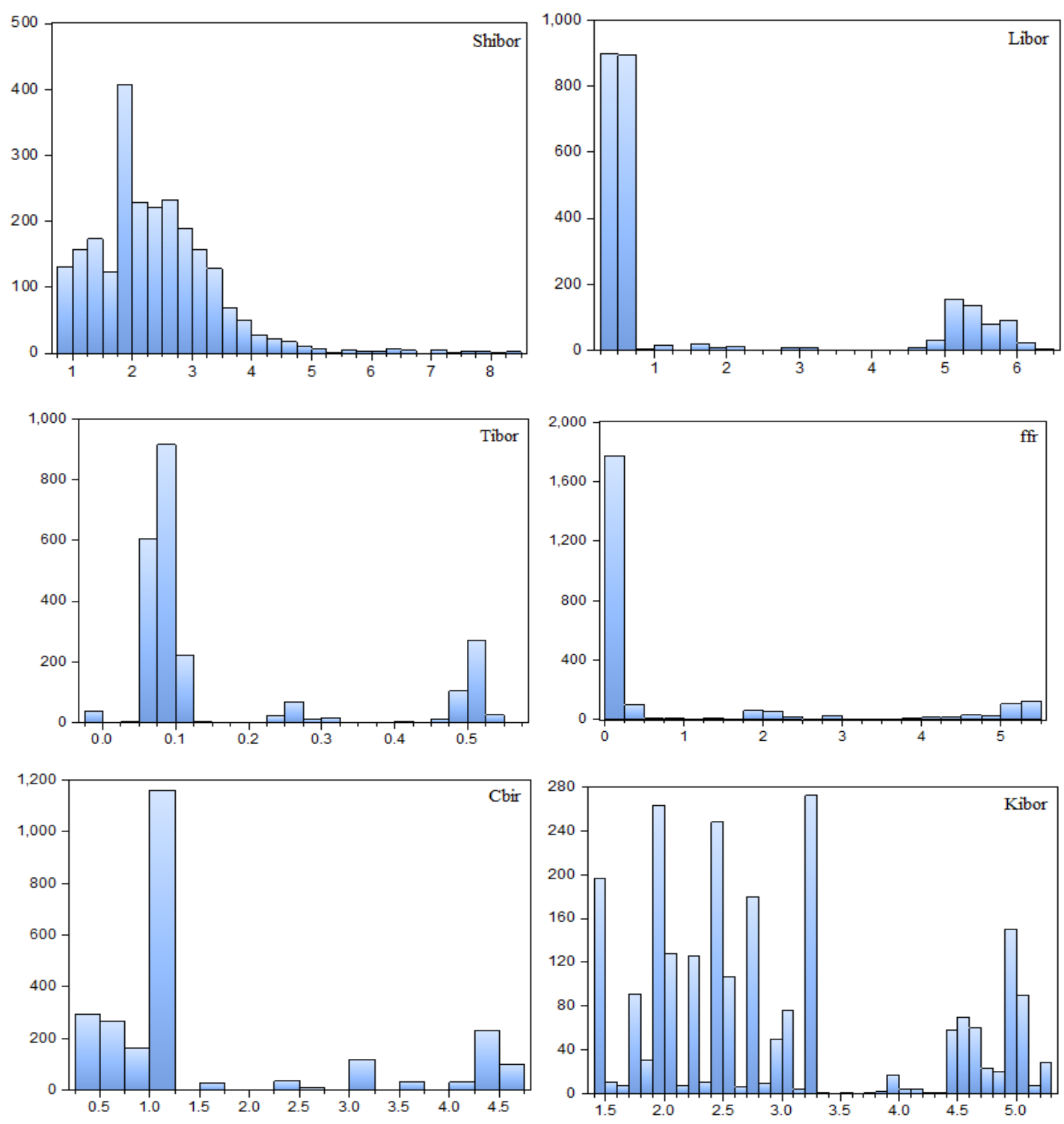

Figure 2. Mean of inter-bank offered rate histogram

Table 5. Result of Fat-Tail J-B Test statistic data

\begin{tabular}{llrrrrr}
\hline \multicolumn{7}{c}{ Fat-Tail Test } \\
\hline & Shibor & \multicolumn{1}{c}{ Libor } & \multicolumn{1}{l}{ Tibor } & \multicolumn{1}{c}{ FFR } & \multicolumn{1}{l}{ Cbir } & \multicolumn{1}{c}{ Kibor } \\
Jarque-Bera & 2957.965 & 708.517 & 833.019 & 1569.841 & 744.190 & 260.417 \\
Probability & 0.000 & 0.000 & 0.000 & 0.000 & 0.000 & 0.000 \\
\hline
\end{tabular}


The above results show that each mean of inter-bank offered rate shows a fat-tail characteristic. It does not meet the null hypothesis (normal distribution), indicating that each inter-bank offered rate is non-normal distribution.

\subsubsection{Variance Test}

The established time series model needs autoregressive conditional heteroskedasticity test. The method is checked by ARCH LM test. The null hypothesis is that the residuals do not have ARCH effect until the p-order. It is necessary to ensure that the residual sequence has ARCH effect before the GARCH model is established. Firstly, this paper establishes a linear regression of each inter-bank offered rate. For instance, A linear regression equation is built for Shibor and ARCH effect test results are shown in Table 6:

$$
\text { Shibor }=c+\text { Shibor }(-1)
$$

Table 6. Result of ARCH Effect Test

\begin{tabular}{lcccccc}
\hline & \multicolumn{7}{c}{ ARCH effect } \\
\hline & Shibor & Libor & Tibor & FFR & Cbir & Kibor \\
Lag Order & 1 & 1 & 1 & 1 & 1 & 1 \\
P-value & 0 & 0 & 0 & 0 & 0 & 0 \\
\hline
\end{tabular}

The P-value of all sequences test is 0 , so reject the null hypothesis. Therefore, these sequences all have ARCH effect.

\subsubsection{Serial Correlation Test}

This paper uses LM to test presence of higher-order serial correlation in the residuals. The null hypothesis is that autocorrelation sequence does not exist until the p-order lag. This paper then performs serial correlation LM test on Linear regression equation (1). The result is listed in Table 7.

Table 7. Test Result of LM Serial Correlation

\begin{tabular}{lcccccc}
\hline & \multicolumn{7}{c}{ LM test } \\
\hline & Shibor & Libor & Tibor & FFR & Cbir & Kibor \\
Lag Order & 1 & 1 & 1 & 1 & 1 & 1 \\
P-value & 0 & 0 & 0 & 0 & 0 & 0 \\
\hline
\end{tabular}

Test results show that all P-values are 0 . Therefore, there is no serial correlation in sequence in setting the significance level. Based on the above test results, the mean of data of six different inter-bank offered rates can establish the GARCH model.

\subsubsection{GARCH Family Model}

When establishing the GARCH Family model, this paper builds GARCH, TARCH, EGARCH and PARCH model. Since the data are non-normally distributed, the $t$ distribution is selected. This paper selects the best fitting degree and the highest $R^{2}$ to calculate the VaR value. Regression equation is the same with equation (1). The results are shown in Table 8.

Table 8. GARCH Family Model results

\begin{tabular}{lllllll}
\hline \multicolumn{7}{c}{ GARCH Family Model Results } \\
\hline & Shibor & Libor & Tibor & FFR & Cbir & Kibor \\
GARCH & 0.977245 & 0.999783 & 0.999056 & $\mathbf{0 . 9 9 9 7 6 7}$ & $\mathbf{0 . 9 9 9 8 8 9}$ & $\mathbf{0 . 9 9 9 6 4 7}$ \\
Adj. $R^{2}$ & 0.977235 & 0.999783 & 0.999055 & 0.999767 & 0.999889 & 0.999647 \\
\hline
\end{tabular}




\begin{tabular}{lllllll}
\hline TARCH & 0.977244 & $\mathbf{0 . 9 9 9 7 8 4}$ & 0.999055 & 0.999767 & 0.999889 & 0.999647 \\
Adj. $R^{2}$ & 0.977235 & 0.999784 & 0.999055 & 0.999767 & 0.999889 & 0.999647 \\
EARCH & $\mathbf{0 . 9 7 7 2 5 2}$ & 0.999783 & 0.999056 & 0.999767 & 0.999889 & 0.999647 \\
Adj. $R^{2}$ & 0.977242 & 0.999783 & 0.999055 & 0.999767 & 0.999889 & 0.999647 \\
PARCH & 0.977245 & 0.999783 & $\mathbf{0 . 9 9 9 0 5 6}$ & 0.999766 & 0.999889 & 0.999647 \\
Adj. R ${ }^{2}$ & 0.977236 & 0.999783 & 0.999056 & 0.999766 & 0.999889 & 0.999647 \\
Max of $\mathrm{R}^{2}$ & EARCH & TARCH & PARCH & GARCH & GARCH & GARCH \\
\hline
\end{tabular}

The above results show that each mean of inter-bank offered rate has a most appropriate fit model: Shibor EGARCH model, Libor - TARCH model, Tibor - PARCH model, FFR, Cbir and Kibor - GARCH model. After establishing each data model, the ARCH effect will be re-tested to ensure the elimination of residual variance difference. Detailed are shown in Table 9.

Table 9. ARCH Effect results after establishment of GARCH Family Model

\begin{tabular}{|c|c|c|c|c|c|c|}
\hline \multicolumn{7}{|c|}{ Re-Test of ARCH Effect } \\
\hline & Shibor & Libor & Tibor & FFR & Cbir & Kibor \\
\hline Lag order & 1 & 1 & 1 & 1 & 1 & 1 \\
\hline $\begin{array}{l}\text { Prob. } \\
(1,2373)\end{array}$ & 0.8842 & 0.9765 & 0.7001 & 0.8774 & 0.8673 & 0.6779 \\
\hline $\begin{array}{l}\text { Prob. } \\
\text { Chi-Square (1) }\end{array}$ & 0.8841 & 0.9765 & 0.7000 & 0.8773 & 0.8673 & 0.6778 \\
\hline
\end{tabular}

As shown in Table 9, all data are not significant at the significance level. Therefore, there is no ARCH effects in sequences. The model is established successfully.

\subsubsection{VaR Numerical Analysis}

The static prediction makes use of the actual value of lagged dependent variable. Therefore, the static prediction results are more accurate. According to each model's quantile $T$ values, the degree of freedom ( $t$ ) of each model is calculated in Table 10.

Table 10. Degree of freedom (t) of each inter-bank offered rate model

\begin{tabular}{ccccccc}
\hline \multicolumn{7}{c}{ Degree of freedom $(\mathrm{t})$} \\
\hline Type & Shibor & Libor & Tibor & FFR & Cbir & Kibor \\
Degree of Freedom $\mathrm{t}$ & 2.1887 & 2.6713 & 2.7954 & 2.6553 & 1.7314 & 2.9165 \\
\hline
\end{tabular}

This paper uses the GARCH model predictions and degree of freedom $t$ to calculate the VaR of each mean of inter-bank offered rate at the 95\% confidence level. The detailed result is covered in in Figure 3 and Table 11. 

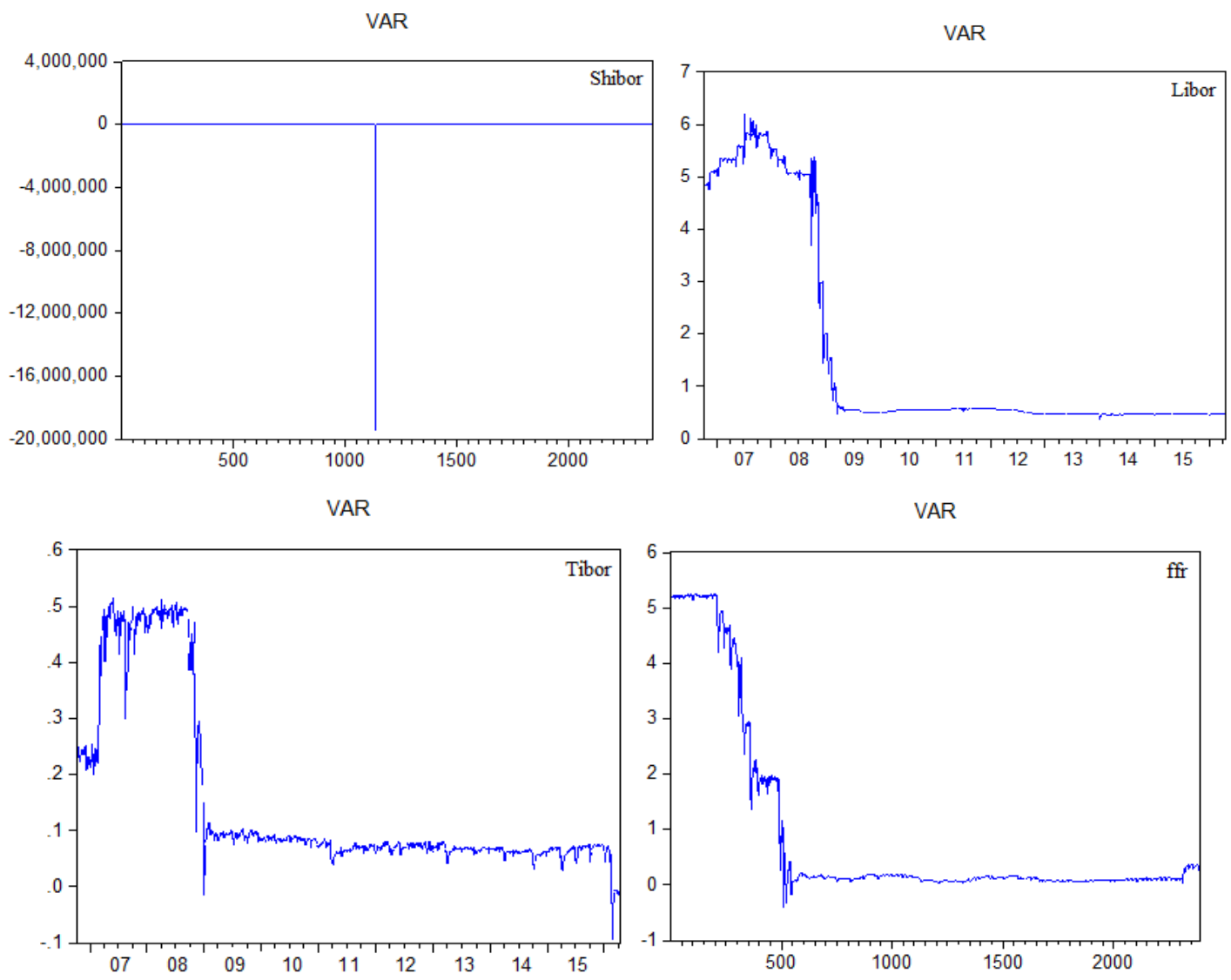

VAR
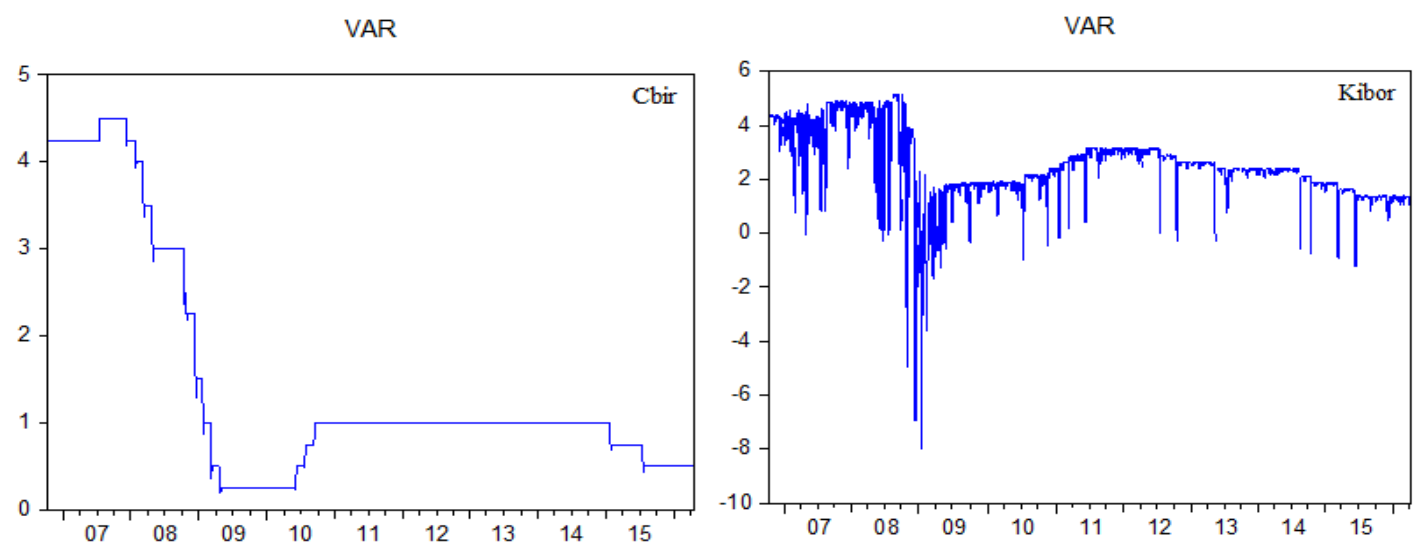

Figure 3. VaR of Test Pattern of Six Different Mean of Inter-Bank Offered Rate

Table 11. VaR of sensed value of six different mean of inter-bank offered rate

\begin{tabular}{lrccccc}
\hline \multicolumn{1}{c}{ VaR value } \\
\hline & \multicolumn{1}{c}{ Shibor } & Libor & Tibor & \multicolumn{1}{l}{ FFR } & \multicolumn{1}{l}{ Cbir } & \multicolumn{1}{l}{ Kibor } \\
Mean & -8599.579000 & 1.587277 & 0.150259 & 0.910232 & 1.486002 & 2.391523 \\
Median & 1.989653 & 0.544787 & 0.075090 & 0.128699 & 0.997561 & 2.351803 \\
Maximum & 7.774895 & 6.053758 & 0.514064 & 5.252068 & 4.497392 & 5.151156 \\
Minimum & -19472218.000000 & 0.251104 & -0.094854 & -0.403840 & 0.178785 & -7.973428 \\
Std. Dev. & 399969.800000 & 1.967218 & 0.154701 & 1.671882 & 1.333411 & 1.384348 \\
\hline
\end{tabular}


VaR experimental data show that Shibor has the maximum data range and the gap between the Shibor's VaR and other inter-bank offered rates' VaR is huge. There are great outliers in VaR's test pattern and sensed value, resulting in the standard deviation of Shibor being 399969.8. The standard deviation of Shibor is almost 20 times of Libor, FFR, Cbir and Kibor. Moreover, the standard deviation of Shibor is almost 200 times of Tibor. The mean volatility of Shibor is significantly larger than the mean volatility of others. Tibor has the minimal interest rate risk. Its VaR's standard deviation is only 0.154701 .

\subsubsection{VaR - Chi-Square Test}

At $95 \%$ confidence level, this paper performs the chi-square test towards VaR in the range of 1-5 degrees of freedom. The test results are listed in Table 12.

Table 12. Chi-Square critical value at $95 \%$ confidence level

\begin{tabular}{cc}
\hline \multicolumn{2}{c}{ Chi-Square Critical Value (95\% Confidence Level) } \\
\hline Df (Degree of Freedom) & $\mathbf{0 . 2 5}$ \\
1 & 5.024 \\
2 & 7.378 \\
3 & 9.348 \\
4 & 11.143 \\
5 & 12.833 \\
\hline
\end{tabular}

Table 12 shows that VaR is less than 1 at $95 \%$ confidence level. When the degree of freedom is equal to 1 , VaR less than the critical value 5.024. These results indicate the data in line with chi-square distribution and experimental data is valid.

\subsubsection{Reanalysis of Shibor after Removing Outlier}

According to above results, the fluctuation range and standard deviation of VaR of Shibor are large enough. However, through the graph of VaR shows that Shibor fluctuates significantly because there are some abnormal values at certain point of time. These abnormal values affect degree of deviation, causing huge level of fluctuation range and standard deviation of VaR. In order to remove the VaR's outliers, this paper reanalyzes the VaR. In summary, this paper performs VaR-GARCH test after removing the abnormal values of Shibor. This paper processes the original data of Shibor to retest the data. Data which are 3 standard deviations away from the mean are eliminated. Table 3 shows that the mean of Shibor is 2.353897 and standard deviation is 1.012186. Therefore, the range is [- 0.68266 , 5.390455]. After removing 33 outliers, the remaining observations of Shibor is 2,344.

\subsubsection{GARCH Family Model for New Data}

This paper establishes the GARCH family model for the new data. The regression equation is same to equation (1). The results are listed in Table 13.

Table 13. New sequence of Shibor - GARCH Family Model

\begin{tabular}{cc}
\hline & Shibor \\
\hline GARCH & 0.978045 \\
Adj. $\mathrm{R}^{2}$ & 0.978036 \\
TARCH & 0.978045 \\
Adj. $\mathrm{R}^{2}$ & 0.978035 \\
EARCH & $\mathbf{0 . 9 7 8 0 5 3}$ \\
Adj. $\mathrm{R}^{2}$ & 0.978044 \\
PARCH & 0.978044 \\
Adj. $\mathrm{R}^{2}$ & 0.978035 \\
Selecting maximum of $\mathrm{R}^{2}$ & $\mathrm{EARCH}$ \\
Quantile T & 3.661678 \\
Degree of freedom t & 2.18971995366 \\
\hline
\end{tabular}


The results of GARCH family model indicates that the optimal model for the new sequence of Shibor is EARCH model. The degree of fitting is $97.8052 \%$. This paper then performs ARCH effect test again. The results are listed in Table 14.

Table 14. Result of retest ARCH Effect

\begin{tabular}{cc}
\hline & Retest of ARCH Effect LM \\
\hline & Shibor \\
Lag Order & 1 \\
Prob. F (1,2373) & 0.8879 \\
Prob. Chi-Square (1) & 0.8879 \\
\hline
\end{tabular}

The new sequence of Shibor is not significant at the 95\% significance level, indicating that there is ARCH effect. EGARCH model is established successfully. This paper uses EGARCH model to calculate VaR. The results are listed in Figure 4 and Table 15.

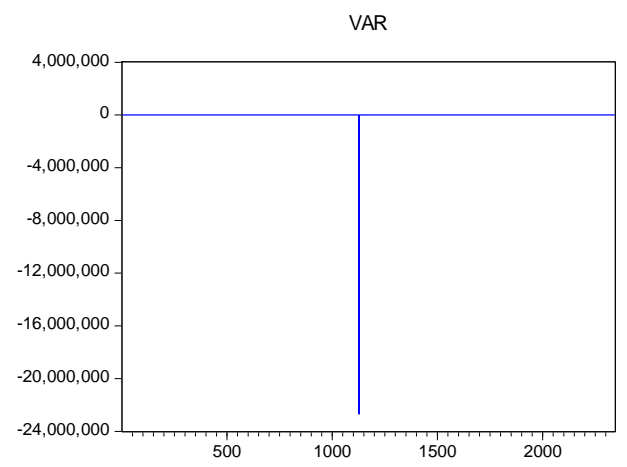

Figure 4. New Test Pattern of Shibor Sequence's VaR

Table 15. Sensed value of mean of Shibor VaR

\begin{tabular}{cc}
\hline & VaR \\
\hline & Shibor \\
Mean & $-10,195.850000$ \\
Median & 1.978386 \\
Maximum & 4.701869 \\
Minimum & $-22,688,294.000000$ \\
Std. Dev. & $469,370.200000$ \\
\hline
\end{tabular}

According to the experimental results of VaR, the fluctuation range of VaR is larger and after the removing of abnormal value in original Shibor sequence. Moreover, volatility of risk is higher than before. The risk characteristics of Shibor remains significant compared with the other five inter-bank offered rate. Chi value is less than 1 at $95 \%$ confidence level according to chi-square test. Therefore, the sequence is in line with chi-square distribution. This paper attempt to remove the abnormal value in original Shibor sequence's VaR and observes the remaining VaR statistical characteristics. The standard deviation of new Shibor's VaR is between 2 and 3, exceeding other five different interbank offered rates. The fluctuation risk of Shibor remains the largest. 


\subsection{Summary of Empirical Analysis}

This paper uses VaR-GARCH model to analyze six different inter-bank offered rates' risk characteristics. The subjects are the mean of inter-bank offered rates of Shanghai, London, Japan, the United States, Toronto, Seoul. Empirical analysis finds the following facts.

1. Shibor has the maximum data range and the gap between the Shibor's VaR and other inter-bank offered rates' VaR is huge.

2. The mean of original Shibor sequence is stationary. Libor, Tibor, FFR, Cbir and Kibor all have a unit root, indicating that each of them is first-difference stationary.

3. Each mean of inter-bank offered rate shows fat-tail characteristic. It does not meet the null hypothesis of normal distribution, indicating that each of inter-bank offered rate is non-normal distribution.

4. All regression equations' residual series are tested by ARCH-LM, showing that there is no ARCH effect. Moreover, it passes LM test and thus there is no autocorrelation sequence. It complying with the requirements of GARCH model. Since the data are non-normally distributed, the t distribution is selected. This paper selects the best fitting degree and the highest $R^{2}$ to calculate the VaR value. Six different mean of inter-bank offered rate have a best fit model. After establishing each data model, the ARCH effect will be re-tested to ensure the elimination of residual variance difference.

5. This paper uses static prediction method to predict each set values. This paper uses the GARCH model predictions and degree of freedom t to calculate the mean of each inter-bank offered rates' VaR at the $95 \%$ confidence level. For Libor, Tibor, FFR, Cbir and Kibor. The range of fluctuation of VaR is small and the degree of dispersion is small. Shibor has the maximum data range and the gap between the Shibor's VaR and other inter-bank offered rates' VaR is huge. Shibor fluctuate significantly because there are some abnormal values at certain point of time. VaR is relatively stable at remaining time. After the removal of abnormal values, the new VaR-GARCH model still has a large risk characteristic. After using two different ways to remove the abnormal value, the fluctuation of Shibor is still more than the other five groups of data.

In summary, Shibor has the greatest risk characteristic among these six different inter-bank offered rates. Moreover, there are ultra-high risk point in Shibor. If there is no reasonable risk management, the organization and market will suffer from interest rate risk which will cause financial loss. In the other five groups overnight rates, the Tokyo overnight call rate risk is the minimal. The other four groups of the overnight rates' fluctuation risk and the degree of dispersion are relatively small.

\section{Conclusion and Policy Implications}

Empirical results show that Shibor is still at a higher risk status than Libor, Tibor, FFR, Cbir and Kibor. Shibor need to incorporate the operation mechanism, the local lending market and financial market whose inter-bank offered rate has lower risk. Combined with the Shibor and five international financial centers' inter-bank offered rates, this paper proposes the following policy implications:

\subsection{Improve the Existing Quotation Mechanism}

The improvement of existing quotation mechanism for Shibor can be divided into three aspects i.e., quotations, supervision, risk control.

1. Quotations: Valuation Pricing / Trading Value Pricing: For the inter-bank offered rate generated from valuation pricing, there are no regulations to compel the bank to make a deal using the above rate. This will result in the difference between the real transaction rate and the rate generated from valuation pricing, meaning that the inaccuracy of valuation pricing of inter-bank offered rate. However, if the real rate is adopted to price, not all of the term can use the same pricing rules since each term of lending transaction does not match each other. Moreover, it can prevent the conspiracy trading between inter-bank trading agency from intentionally using a desired price to make transactions. China can improve the existing valuation pricing basis as well as looking for appropriate product range for the actual price quote. Reducing the difference between the actual price and valuation pricing. Furthermore, as interest rate market grows, China should consider expanding the consisting members of the bank in the group to offer Shibor pricing. There are two benefits from it. Firstly, the quote of interest rate can be more complete because it truly reflects supply and demand in the market situation. Secondly, this action can enhance the difficulty of some individual institutions which want to manipulate the quoted price of interest rate.

2. Supervision System: With the promotion of the marketization of interest rates, the working group in Shibor 
should update management and monitoring systems, i.e., upgrading the calculation of pricing and strengthening management of interest rate quotes. Moreover, China should establish strict regulations about supervision and management of interest rate such as establishment of supervision department. The supervision department should make timely and appropriate response to avoid any irregularities. It need to ensure that these measures are effectively to enhance the quality of quoted price of Shibor.

3. Risk Control: Shibor has experienced abnormal VaR at several time. Therefore, it may need the invention of central bank to deal with the extreme outliers of interest rate. Since China is in the process of marketization of interest rates, it is vital to control risk. The central bank should set up a mechanism to monitor the real-time price situation of Shibor. If the quoted price is not in accordance with the current economic environment or financial market demanded, the central bank should amend it properly to reduce the Shibor volatility's abnormal change. China should promote the market-oriented interest rate process. The central bank should promote the Shibor developments as an inter-bank offered rate and expand the scope and influence of Shibor and enhance the opportunity of Shibor as a benchmark interest rate.

\subsection{Strengthen Market Construction}

This paper has referred to several financial markets which have all achieved marketization of interest rate. China is still in the process of marketization of interest rate. Therefore, there are still many areas which need to be improved. With the development of China's economy, the objective of development of interest rate market is marketization of interest rate. In order to reduce the risk of fluctuations in interest rates, both financial markets and interest rate market must be strengthened at the same time. Improving the overall environment can contribute directly to the goal of maintaining interest rates. Appealing to more foreign financial institutions and financial activities, China's financial market should provide excellent liquidity and comprehensive policies. Abundant market resources and foreign activities will promote the construction of market and development of China's economy. There are large and frequent number of transactions contributing to adjustment of interest rate mechanism. Eventually, the marketization of interest rate will be realized.

\section{References}

Engle, R. (1982). Autoregressive conditional heteroscedasticity with estimates of the Variance of United Kingdom inflation. Journal of Finance, 50(3), 821-851. http://dx.doi.org/10.2307/1912773

$\mathrm{Gu}, \mathrm{Q}$. (2015). Interest risk in Inter-bank market in China based on VaR model. Jönköping University.

Nelson. (1991). Conditional heteroskedastic in asset returns: a new approach. Econometrica, (59), 347-370. http://dx.doi.org/10.2307/2938260

Neupane, S. (2011). Examining Volatility of Interbank Rate in Nepal. NRB Economic Review, 3(1).

Olowe, R. A. (2011). Inter-Bank Call Rate Volatility and the Global Financial Crisis: The Nigerian Case. International Journal of Economics and Finance, 3(1), 289-296. http://dx.doi.org/10.5539/ijef.v3n1p283

Porter, N., \& Xu, T. (2009). What Drives China’s Interbank Market?. IMF Working Paper.

Radham S., \& Thenmozhi, M. (2006). Forecasting short term interest rates using ARMA, ARMA-GARCH and ARMA-EGARCH models. SSRN Electronic Journal.

Sánchez-Fung, José R. (2004). Daily Interbank Rate Determination and Volatility in a Banking Crisis. Economics Discussion Papers.

Yang, J., \& Zhang, S. (2010). VaR Model Based on GARCH Approach and Extreme Value Theory with Application in Chinese Interbank Offering Market. Gastroenterology, 14(14), 1-5. http://dx.doi.org/10.1109/iciecs.2010.5677862

Zakaran. (1990). Threshold Heteroskedastic Model. INSEE, Paris. 